fore this monograph can be recommended without reservation to those interested. J. N. BLAU

Tumors of the Parathyroid Glands. Atlas of Tumor Pathology, Second Series, Fascicle 14. By Benjamin Castleman and Sanford I. Roth. (Pp. 94; illustrated; \$4.50.) Washington: Armed Forces Institute of Pathology. 1978.

This slim fascicle is an excellent summary and atlas of its subject, as would be expected by those who knew the first edition by Castleman alone, now long out of print. In addition to the valuable practical exposition there are interesting sections on the history of hyperparathyroidism and the possible functional cycle of parathyroid cells - the latter somewhat speculative. One may disagree with the authors on the emphasis on mitotic activity as the single most valuable point in diagnosing carcinoma, consider their restriction on the use of the term clear cell unnecessary, the description of colloid somewhat scrappy, and the treatment of tertiary hyperparathyroidism perfunctory. However, it is a book that all concerned with the practical management of hyperparathyroidism-physicians and surgeons as well as pathologistswill find invaluable.

J. F. SMITH

Textbook of Diagnostic Cytology. Edited by M. Y. Ali. (Pp. x + 371; illustrated; price not stated.) Sydney: The New South Wales Institute of Technology. 1978.

This book has been written by 14 Australian authors primarily for students of diagnostic cytology at the New South Wales Institute of Technology. The first part describes general principles of pathology relevant to the subject. This provides a suitable introduction for the student of medical laboratory science. The chapter on cellular responses to therapeutic measures in particular will also be of interest to the cytopathologist. The second section is on cytodiagnosis. The subject is presented concisely, and a good balance is maintained between historical facts, definitions, references, and descriptions of histological and cytological appearances. The cytology of gynaecological material is covered adequately but other anatomical sites get only brief attention.

Unfortunately, the prose style in some chapters is cumbersome, which discourages cover-to-cover reading. The quality of the illustrations is variable, and they are mostly in black and white. This economy is probably relevant to the price of the book, which is not stated, but with a soft cover one hopes it will be modest. This book contains a lot of information and will be useful to cytotechnicians and pathologists in training. It is a welcome addition to a subject which is poorly provided with up-to-date textbooks.

ELIZABETH HUDSON

Hospital-Acquired Infections: Guidelines to Laboratory Methods. Edited by M. T. Parker. (Pp. 63; Sw.Fr. 8.) Copenhagen: WHO. 1978.

The title of this short and useful book is a little misleading. Although the application of laboratory methods to the control of hospital acquired infection forms the longest and most successful chapter, much else receives attention. The causes and sources of hospital infection are succinctly described, and advice is given on the surveillance, investigation, and control of outbreaks of infection in hospital. Naturally, in a book of only 52 pages of text there is no room for detail. However, the authors, who represent many of the countries in Europe, have achieved a uniform approach and provide a sound guide. Their advice accords in general with British practice except that they recommend smallpox vaccination to all new entrants to the hospital service and talk of testing autoclaves with bacterial spores, both procedures surely now outdated.

This book should be recommended to clinical and laboratory staff and may help to stimulate a common standard of practice in European hospitals.

\section{P. SANDERSON}

Clinical Tests of Gastric Secretion. History, Methodology and Interpretation. By J. H. Baron. (Pp. x + 277; illustrated; 12.50.) London: The Macmillan Press Ltd. 1978.

Dr J. H. Baron has written an excellent book. In 270-odd pages, and supported by 1287 references, he has provided a detailed analysis of gastric secretory tests, dealing mainly with acid output, and also with pepsin and gastrin measurements. The book opens with a short physiological introduction and goes on to deal in a practical manner with all the methods in use at present for the recording of gastrin secretory function. A section on the diagnostic value of gastric secretion tests follows, the author ruthlessly eliminating most conditions associated with a pathological response to acid-pepsin attack as being diagnosable by secretory tests. The section contains many detailed tables. If one is looking for possible diagnostic clues this makes pretty arid reading, but perusal of this part of Dr Baron's book provides much food for thought for the clinical researcher interested in the aetiology and acid-pepsin diseases. The last section, which deals with management, describes the role of secretory tests in the surgical and post-surgical patient. This book promises to be a standard text on its subject and should be available in all departments of clinical pathology that deal with peptic ulcer patients.

$$
\text { J. J. MISIEWICZ }
$$

Prenatal Pathology-Fetal Medicine. By T. V. N. Persaud. (Pp. xi + 199; illustrated; \$23.) Springfield, Illinois: Charles C. Thomas. 1979.

This is a 199-page hardback with 27 pages of references written by an anatomist, a cytogeneticist, and a paediatrician in Winnipeg. Almost all the illustrations, apart from those related to chromosomes, are borrowed.

It is uneven and reads like a series of lectures to students. The sections on embryogenesis and the early concepts are clear and critical but the clinical chapters are less so. They describe fetoscopy as a 'promising development'! The eight pages on common neonatal problems are an embarrassment: do we need to be told that jaundice is a yellowish colouring of the skin?

It rightly discusses intrauterine growth retardation but goes direct to biochemical tests of fetal state and maturity, discussing placental lactogen but not oestriols.

The book has attempted too much and failed but is a good source of basic references into 1977 to have available in a departmental library.

$$
\text { J. L. EMERY }
$$

\section{Correction}

British Medical Bulletin, Volume 34, No. 3. September 1978.

The HLA System (Pp. 213-324; UK £5.00, other countries $£ 6.00$, USA and Canada $\$ 12.50$. London: Medical Department, The British Council. 1978.

It is regretted that some of the above details were incorrect in the review published in the June issue of this journal (page 638). 